\title{
REPRESENTACIONES DE LA GUERRA CIVIL ESPAÑOLA EN MANUALES DE HISTORIA DEL FRANQUISMO TEMPRANO
}

\section{Representations of the Spanish Civil War in early Francoist bistory textbooks}

\author{
Christian RoITH \\ Universidad de Almería
}

Correo-e: chroith@ual.es

Recepción: 27 de noviembre de 20I6. Envío a informantes: 9 de diciembre de 2016.

Aceptación definitiva: 20 de mayo de 2017

RESUMEN: Los manuales escolares constituyen unas fuentes idóneas para comprender las idiosincrasias de determinados periodos históricos, porque permiten examinar las ideologías, los conceptos y valores de los grupos sociales en el poder. Los manuales escolares que se utilizaron en las zonas ocupadas por las tropas nacionalistas bajo el comando del general rebelde Francisco Franco y en toda España después de su victoria nos permiten identificar las características de la ideología franquista. El análisis del material original coleccionado y clasificado por el proyecto de investigación MANEs, así como la revisión de estudios teóricos, demuestran que los manuales escolares franquistas reprodujeron ampliamente contenidos procedentes del periodo monárquico anterior a la Segunda República. Las representaciones de la Guerra Civil en estos manuales condensan los principios doctrinales más importantes de la dictadura franquista y revelan las diferencias ideológicas existentes entre las diferentes tendencias presentes en el régimen. Además, el análisis de los textos muestra que el adoctrinamiento ideológico mediante los manuales escolares fue un elemento esencial en los esfuerzos totalitarios del régimen de Franco.

Palabras Clave: Historia; España; franquismo; manuales escolares.

Aвstract: Textbooks are effective tools to understand the idiosyncrasies of certain historical time periods as they allow us to examine the ideologies, concepts and values of the social groups in power. Those textbooks which were in use in the areas occupied by the Fascist National troops under the insurgent General Francisco 
Franco's command and in all of Spain after his victory permit us to draw conclusions about the characteristics of the Francoist ideology. The analysis of original material collected and classified by the Spanish research project of textbooks (MANEs), as well as the review of theoretical studies demonstrates that Francoist schoolbooks to a large extent reproduced contents proceeding from the monarchic period before the Second Republic. The representations of the Civil War in these textbooks condense the most important doctrinal principles of the Franco dictatorship and reveal the existing ideological differences between different tendencies represented in the regime. Furthermore, the analysis of these texts shows that the ideological indoctrination through schoolbooks was an essential element of the totalitarian efforts of the Franco regime.

KEY wORDs: History; Spain; Francoism; text books.

\section{Introducción}

7 l debate académico sobre la Guerra Civil española y la dictadura de 1 Franco ha producido un gran número de contribuciones en los últimos años. No solamente se publicaron numerosos estudios políticos e históricos generales, sino también trabajos de investigación especializados. Los historiadores de la educación en España se centraron sobre todo en la persecución y depuración del profesorado republicano durante la dictadura ${ }^{\mathrm{I}}$, mientras que un número más reducido de investigadores analizó los manuales escolares franquistas para llegar a una comprensión más profunda de la idiosincrasia de este periodo histórico. Este procedimiento se fundamenta en la suposición de que la ideología de los grupos sociales en el poder se refleja en los manuales escolares de una sociedad, como igualmente sus conceptos relacionados con la transmisión de sus valores a las nuevas generaciones. Como explica un historiador español renombrado,

crecemos con una serie de prejuicios asumidos como conocimiento, que la educación se encarga de legitimar. El objetivo final de este adoctrinamiento no son la nación y el patriotismo, sino que éstos se utilizan generalmente para transmitir al niño convicciones que tienen que ver con intereses sociales concretos que impregnan la visión del pasado que se le inculca².

Por ejemplo, Ramos Zamora, Sara: «Control y represión: estudio comparado de los resultados de la depuración del magisterio primario en España», Revista Complutense de Educación, vol. I7, n. ${ }^{\circ}$ I (2006), pp. I69-I84 y «Acusaciones profesionales vertidas contra el magisterio primario por el gobierno franquista en el proceso depurativo: El caso de Castilla-La Mancha», Historia de la Educación: Revista Interuniversitaria, n. ${ }^{\circ} 25$ (2005), pp. 343-369. También MarTín ZúÑIGa, Francisco; Grana Gil, Isabel y SAnchidrián Blanco, María del Carmen: «La depuración franquista de los docentes: control y sometimiento ideológico del profesorado de instituto", Historia de la Educación: Revista Interuniversitaria, n. ${ }^{\circ} 29$ (20IO), pp. 24I-258 y FERnÁndez SORIA, Juan Manuel y AgULLó DíAz, María del Carmen: Maestros valencianos bajo el franquismo: la depuración del magisterio, 1939-1944, Valencia, Diputació de València, Institucio Alfons el Magnanim, I999.

Fontana LÁzARo, Josep (ed. y autor de la introducción): Enseñar historia con una guerra civil por medio, Barcelona, Editorial Crítica, 1999, p. 7. 
CHRISTIAN ROITH

Por esta razón, este estudio ofrece al principio un resumen de la política franquista del libro escolar. A continuación, se revisan varios estudios de manuales escolares de la época franquista; algunas de las hipótesis fundamentales de estos trabajos se utilizarán como categorías analíticas para la investigación realizada en la tercera parte: el análisis de las representaciones de la Guerra Civil española en 26 manuales escolares franquistas utilizados durante y después de la guerra. Estos manuales se seleccionaron entre 36 manuales de historia que pertenecen a la colección del proyecto de investigación MANEs que se encuentra en la Biblioteca de la Universidad Nacional de Educación a Distancia (UNED) en Madrid.

Estos manuales escolares se analizaron teniendo en cuenta las siguientes cuestiones, entre otras: ¿Cómo construyen los textos sobre la Guerra Civil la identidad nacional del nuevo Estado dictatorial mediante la representación del enemigo? ¿Qué revelan estos textos sobre los diferentes elementos que constituyen la ideología franquista? ¿Existen paralelismos a tendencias ideológicas anteriores? $¿$ Se pueden identificar diferencias entre los textos que se pueden interpretar como debidas al predominio de diferentes tendencias presentes en el franquismo o simplemente al paso del tiempo? El estudio terminará con una reflexión sobre la cuestión, hasta qué punto se puede considerar la interpretación franquista de los acontecimientos históricos como representativa para la adulteración de la historia en el interés de un régimen dictatorial.

\section{La política franquista del libro escolar}

Mientras que el debate académico sobre las características más destacadas de la España franquista se sigue desarrollando en la actualidad, no cabe duda de que diferentes fuerzas sociales y políticas llegaron a formar una alianza bajo el liderazgo de Francisco Franco, entre las cuales se encontraron conservadores, tradicionalistas, católicos autoritarios y un movimiento supuestamente innovador como los falangistas. Las características más importantes que se mantuvieron durante los cuarenta años de la dictadura fueron el antiliberalismo, el rechazo de la democracia representativa, el antisocialismo, el anticomunismo y el apoyo incondicional de un líder llamado "Caudillo». Al menos durante la guerra y los primeros años de la dictadura, los rebeldes nacionalistas fueron aliados y admiradores de los regímenes totalitarios de la Alemania nacionalsocialista y de la Italia fascista. Cuando el declive de los poderes del Eje quedó evidente, otro elemento del franquismo que no jugó un papel decisivo en las dictaduras alemana e italiana empezó a imponerse: el fundamentalismo católico.

Los rebeldes nacionalistas consideraron los libros escolares como un instrumento valioso en su lucha por la dominación ideológica de España. A principios del mes de septiembre de 1936, es decir, ni siquiera dos meses después del inicio del conflicto, la Junta para la Defensa Nacional en Burgos publicó varios decretos: el nuevo régimen ordenó, en primer lugar, la «incautación y destrucción de cuantas obras de matiz socialista y comunista se hallen en bibliotecas ambulantes y escuelas», y permitió a cada profesor la publicación de libros de texto, siempre que en 
ello «no haya cosa alguna que se oponga a la moral cristiana ni a los sanos ideales de la ciudadanía y patriotismo»3. Un año más tarde, la ambición de la dictadura llegó incluso más lejos: un nuevo decreto, publicado el 2i de septiembre de 1937, abolió la libertad de editar manuales escolares bajo la rígida vigilancia de la censura y propuso la elaboración del libro de texto único, el llamado «Libro de España», que se debió de convertir en la «guía y orientación de la enseñanza patriótica que el Maestro ha de transmitir al alumno» ${ }^{4}$. Solamente unos pocos meses más tarde, el II de abril de 1938, el Ministerio de Educación Nacional, responsable de los territorios bajo el control del ejército de Franco, encargó al recientemente fundado Instituto de España la edición de varios manuales escolares para los diferentes niveles de la educación primaria que se quisieron introducir como obligatorios para escuelas públicas y privadass. No obstante, este intento de introducir el texto único según el ejemplo de los Estados fascistas aliados fracasó inmediatamente. Los «autores y editores..., presionaron para poder seguir con sus actividades» ${ }^{6}$ y solamente dos meses después de publicar el decreto mencionado, una nueva disposición permitió la venta de determinados libros de texto para la escuela primaria para «no inferir, en tanto sea posible conjurarlo, graves daños a la industria editorial española...» Esta autorización se mantuvo incluso después de la publicación de los primeros libros de texto por el Instituto de España y significó el abandono de la intención de introducir el texto estándar para todas las escuelas. Hay diferentes opiniones respecto a los motivos para esta nueva política: Manuel de Puelles considera que «la uniformidad de contenidos pretendida por el texto único se logró por otro camino: el de la censura previa de todos los libros escolares ${ }^{8}$, mientras que Carmen Diego opina que la razón más importante para el intento de introducir el libro de texto único y el posterior abandono de esta política fue económica, porque las ventas de libros para la educación primaria fueron muy rentables. Un estudio de José Ramón López coincide con esta última opinión y aporta la cita de un alto responsable del régimen franquista que se opuso al proyecto del libro único ${ }^{\text {To }}$.

http://www.represura.es/documentos_1936_septiembre.html [Consulta del 22 de marzo de 2017]; estos decretos se reproducen también en de Puelles Benítez, Manuel: «La política del libro escolar. Del franquismo a la restauración democrática», en Escolano Benito, Agustín: Historia ilustrada del libro escolar en España. De la posguerra a la reforma educativa, Madrid, Fundación Germán Sánchez Ruipérez, 1998, p. 5 I.

4 Boletín Oficial del Estado, 22 de septiembre, 1937, citado en Puelles Benítez, Manuel: «La política del libro escolar», p. 52.

Ibidem.

6 Diego Pérez, Carmen: «Dictamen y dotación de libros de texto desde la Guerra Civil hasta la creación del Consejo Nacional de Educación", Historia de la Educación: Revista Interuniversitaria, n. ${ }^{\circ}$ I9 (2000), p. 309.

Diego Pérez, Carmen: «El Instituto de España: su labor en pro de los textos únicos de enseñanza primaria», en TiANA FERRER, Alejandro (ed.): El libro escolar, reflejo de influencias pedagógicas e intenciones politicas, Madrid, UNED, 2000, p. 53.

8 Puelles Benítez, Manuel: «La política del libro escolar», op. cit., p. 54.

9 Diego Pérez, Carmen: «El Instituto de España», op. cit., p. 53.

ro López Bausela, José Ramón: La contrarrevolución pedagógica en el franquismo de guerra. El proyecto político de Pedro Sainz Rodríguez, Madrid, Editorial Biblioteca Nueva, 20II, p. I82. 
CHRISTIAN ROITH

El régimen franquista no modificó la política de la censura de los libros escolares en los años posteriores: todos los manuales escolares tenían que someterse a un rígido examen de sus contenidos ideológicos por la administración, complementado por otras instituciones que controlaron, por ejemplo, los libros de texto de gramática -la Real Academia de la Lengua- o libros sobre la catequesis -la Iglesia católica-.

El franquismo en general cambió en algunos aspectos después de la derrota militar del fascismo y del nacionalsocialismo en i945: términos como fascismo, totalitarismo, raza, sangre, imperio, etc., desaparecieron paulatinamente del vocabulario oficial y otras ideas, como el catolicismo, el movimiento, el reino y la subsidiariedad que antes también habían estado presentes, empezaron a usarse con más frecuencia. La intención fundamental detrás de esta modificación del vocabulario oficial fue, en primer lugar, garantizar la sobrevivencia del régimen en las nuevas circunstancias políticas y, más tarde, su consolidación ${ }^{\text {II }}$. La política del libro escolar no cambió esencialmente en estos años, ninguna nueva ley significativa sobre libros escolares se aprobó hasta 1955, cuando unas listas bastante largas con libros de texto autorizados se publicaron. Incluso entre 1957 y 1975, es decir, la llamada fase tecnocrática del régimen franquista, se mantuvieron los principios básicos de la política señalada y se puede observar solamente la mejora de la calidad material de los manuales escolares y una modernización muy cuidadosa de sus contenidos. Al mismo tiempo, el entusiasmo nacionalista y religioso, muy presente en los primeros años de la dictadura, disminuyó ligeramente.

\section{Una revisión de estudios de manuales escolares franquistas}

En lo siguiente se ofrecerá la revisión de una serie de estudios contemporáneos de manuales escolares franquistas con la intención de elaborar un resumen de los enfoques y los resultados de una muestra representativa, aunque no completa, de la investigación histórica realizada en este campo en las últimas dos décadas. Se examinará la posible utilidad de cada uno de los enfoques de investigación para el fin del presente estudio, es decir, el análisis de las representaciones de la Guerra Civil en los libros de texto del franquismo temprano; además, se discutirán algunos resultados de estos estudios en la interpretación de dichos textos.

Un par de estudios interesantes sobre este tema se publicaron en un volumen con una colección de trabajos de investigación titulado El libro escolar, reflejo de influencias pedagógicas e intenciones políticas, editado por Alejandro Tiana Ferrer ${ }^{12}$. El capítulo de Rafael Valls insiste en la necesidad de investigar la cuestión hasta qué punto los manuales de historia determinan e influyen en la memoria individual de estudiantes. En este contexto, el autor considera los libros de texto como «un elemento más, un "lugar de la memoria” más, que contribuye a la formación, y

" Diego Pérez, Carmen: «El Instituto de España», op. cit., pp. 57-58.

${ }_{12}$ Tiana Ferrer Alejandro (ed.): El libro escolar, reflejo de influencias pedagógicas e intenciones políticas, Madrid, UNED, 2000. 
puede que transformación, de tales estereotipos, al menos por lo que se refiere a épocas pasadas $»^{13}$. En la parte sobre los manuales de historia en la época franquista, constata correctamente que la intención fundamental del nuevo orden escolar fue la ruptura radical con la orientación reformista anterior, recuperando las tendencias educativas católicas más tradicionales y antiliberales. A continuación, el autor defiende una hipótesis que habrá que examinar más detalladamente en el siguiente análisis de manuales de historia: «Se puede afirmar, aunque sea de forma simplificadora, que las pequeñas variantes que lentamente fueron apareciendo en los manuales del franquismo a lo largo de las décadas de 1950 y de 1960 son escasamente significativas hasta $1970{ }^{{ }^{14}}$. La argumentación básica de estos libros de texto había sido definida ya en 1939 en un decreto sobre los cuestionarios de historia oficiales para estudiantes de la educación secundaria que determinaron lo siguiente con referencia a la Segunda República: «La II República española: los pseudo-intelectuales ambiciosos y despechados, la masonería y los financieros judíos internacionales hacen caer la monarquía. La Segunda República: sentido anti-católico, antimilitarista y anti-españolista; sus desastres, sus desordenes, sus crímenes» ${ }^{15}$. A continuación se ofrece una descripción del esquema ideológico contenido en los manuales escolares franquistas y el autor destaca de nuevo que los argumentos básicos no cambiaron hasta la muerte del dictador. En un estudio publicado en 2009, el autor vuelve a insistir en su hipótesis expresada en el texto resumido, declarando sobre los manuales de historia del franquismo utilizados en las escuelas españolas entre 1953 y 1970 que «la característica principal de su interpretación es su continuismo respecto de la iniciada con los manuales del plan de 1938. Las escasas variantes introducidas están relacionadas con los adjetivos que se utilizan para definir a los republicanos que, ocasionalmente, adquieren tonos menos descalificadores... $\gg^{16}$. De los resultados presentados por este autor se derivan dos tareas esenciales para la interpretación de los capítulos sobre la Guerra Civil en los manuales de historia franquistas: en primer lugar, habrá que identificar la narración ideológica que estos textos contienen y, en segundo lugar, habrá que intentar confirmar, modificar o rechazar la hipótesis referente a la homogeneidad de los contenidos en estos manuales con la ayuda del material disponible.

Miguel Lacruz Alcocer ofrece en el volumen editado por Tiana Ferrer un trabajo de investigación que parte de la hipótesis de que «con los manuales escolares, igual que si fueran catecismos se formaban las conciencias, se creaba el sentido del bien y del mal, de lo conveniente y de lo irregular, de lo bueno y lo malo, de lo racional o irracional, de tantas cosas $»^{17}$. Según el autor, los libros de texto de lengua

${ }^{13}$ VAlLs, Rafael: «II. La historia enseñada en España a través de los manuales escolares de historia (enseñanza primaria y secundaria)», en Tiana Ferrer, Alejandro (ed.): El libro escolar, p. 49.

${ }_{14}$ Ibidem, p. 56.

is $B O E$ del I4 de abril de 1939 , cit. en ibidem, p. 57.

16 VAlls, Rafael: Historia y memoria escolar. Segunda República, Guerra Civil y dictadura franquista en las aulas, València, Publicacions de la Universitat de València, 2009, pp. 44-45.

${ }_{17}$ Lacruz Alcocer, Miguel: «V. Inculcación ideológica en los manuales escolares de lengua española en la ley de educación primaria de 1945 (cartillas, libros de lectura y manuscritos)», en TiANA Ferrer, Alejandro (ed.): El libro escolar, op. cit., p. 97. 
CHRISTIAN ROITH

española enseñaron a leer con textos vinculados al movimiento nacionalista, es decir, el alumnado se vio expuesto a ideas relacionadas con el nacionalcatolicismo dominante desde la educación primaria. Además, se obligó a los niños a dibujar iglesias, crucifijos y banderas nacionales en su primer libro de ejercicios, de manera que interiorizaran los símbolos de Dios, la nación y la Iglesia con sus primeras letras. Al mismo tiempo se presentó la lengua española como una lengua superior; para ilustrar este punto, el autor cita una enciclopedia contemporánea que declara: «Eres lengua de una raza que un imperio conquistó; eres, pues, idioma-imperio: de un imperio espiritual... Eres lengua sacrosanta; eres lengua tan excelsa que no otra en este mundo que mejor hable al señor... ${ }^{18}$. La mayoría de las lecciones se parecían a sermones que intentaban convencer a los jóvenes estudiantes de convertirse en buenos y trabajadores españoles y patriotas. Estos resultados invitan a buscar similitudes y diferencias entre el vocabulario usado en los manuales escolares para la enseñanza del español mencionados y los libros de texto de historia del mismo periodo histórico.

La manipulación emocional del alumnado mediante imágenes es uno de los temas importantes en un trabajo de investigación de Lara Campos Pérez ${ }^{19}$. La autora comenta al principio de su trabajo que los primeros años del franquismo se caracterizaron por una superabundancia de representaciones del enemigo que se convirtieron en un elemento constante en la imagen del país promocionado por el franquismo. Los manuales escolares de historia no se referían solamente a la edad contemporánea, cuando trataron el tema del enemigo, sino que hablaron igualmente de enemigos históricos de España, de manera que la historia del país se presentó como una lucha continua contra los enemigos. Las razones por las que el «otro», es decir, el enemigo, jugó un papel tan importante en el discurso franquista después de la Guerra Civil podrían deberse, por un lado, a la falta de voluntad de reconciliación que el régimen mostró después de la guerra y, por otro, a la heterogeneidad y la falta de consistencia ideológica que caracterizaron los primeros años del franquismo. La autora interpreta en este sentido la referencia al enemigo como un recurso apropiado que funcionó como un adhesivo social. Los manuales de historia del franquismo temprano representaron los acontecimientos del pasado como una secuencia de batallas entre las fuerzas del bien contra el mal, de manera que el alumnado con edades comprendidas entre los 8 y los I2 años estaba preparado para distinguir los buenos españoles de sus antagonistas. Según Campos, las representaciones iconográficas del enemigo en los libros de texto mostraron dos enfoques diferentes: se mostró al enemigo con una actitud humillada después de ser derrotado por «nosotros», o se representó como un guerrero cruel sin escrúpulos morales ${ }^{20}$. La interpretación franquista del enemigo

${ }_{18} \quad$ Ibidem, p. IOI.

19 Campos Pérez, Lara: «Representando al enemigo: Iconografía del “otro” en los manuales escolares de historia durante el primer Franquismo», ponencia presentada en el I Encuentro de Jóvenes Investigadores en Historia Contemporánea de la AHC, 2008, disponible en http://ifc.dpz.es/ recursos/publicaciones/27/15/20.laracampos.pdf [Consulta del 22 de marzo de 2017].

${ }^{20}$ Ibidem, p. 4. 
político se pareció a la interpretación del pasado, y la Guerra Civil recientemente finalizada se justificó con el pasado guerrero del pueblo español, advirtiendo al mismo tiempo al alumnado que se podrían producir nuevas agresiones en el futuro cercano. Las imágenes correspondientes en los libros de texto contribuyeron a mantener la sensación general de una situación de amenaza contra los españoles y promocionaron el odio contra lo «diferente». Estas imágenes transmitieron un mensaje cruel y agresivo con un efecto inmediato en los niños que textos escritos no habrían conseguido con tanta facilidad. Las imágenes analizadas deshumanizaron a las personas representadas, mostrándolas como monstruos demoniacos o una especie de animales inferiores a los seres humanos, al «nosotros».

El estudio interesante y original de Campos destaca dos aspectos, cuyo exámen detallado puede ser útil en el análisis de los capítulos sobre la Guerra Civil en los manuales escolares de historia franquistas: en primer lugar, habrá que interpretar las descripciones verbales del enemigo, teniendo en cuenta hasta qué punto ofrecen un contraste necesario para la construcción de la nueva identidad nacional. Un aspecto adicional sería el análisis de la contribución de las ilustraciones que acompañan a la creación de esta autopercepción.

Un trabajo de investigación reciente examina el reflejo de los contenidos de manuales de historia franquistas en un libro de ejercicios de una estudiante en un pueblo cerca de Valencia del año $1958^{21}$. Este material muestra, según la autora, que el aprendizaje en las escuelas franquistas significó tomar apuntes y memorizarlos. La moralidad religiosa, cuyos principios para el orden y la disciplina se encontraron escritos a mano frecuentemente repetidos en todo el libro de ejercicios, estructuró la vida escolar. Los manuales de historia ofrecieron narraciones de las victorias de las tropas de Franco que los estudiantes tenían que copiar a mano en su libro de ejercicios; un ejemplo citado por Balaguer documenta el vocabulario sencillo transmitido a los estudiantes, con el que se construía la identidad de los «buenos» nacionalistas, contrapuesta a la de los rojos «malos». Teniendo en cuenta la falta contemporánea de fuentes alternativas, parece justificado suponer que los libros de texto utilizados, combinados con otras actividades bastante monótonas en clase, como los dictados y la copia manual de texto, influyeron de una manera decisiva en el concepto de la historia y la identidad de España que los niños adquirieron, aunque este tema habrá sido ajeno al interés inmediato de los niños, tal y como la autora comenta.

Un grupo de investigación formado por profesores de instituto a mediados de los años 1970 publicó finalmente en el año 2000 su estudio sobre la Segunda República y la Guerra Civil en los textos de bachillerato (1938-1983) que contiene un capítulo que trata de las representaciones de este conflicto bélico en los primeros textos del franquismo ${ }^{22}$. Basándose en una muestra de 23 manuales escolares,

${ }^{21}$ Balaguer Flores, Irene: «La utilización de manuales escolares y los cuadernos para el estudio de la Historia de España desde 1928 hasta la primera etapa del franquismo, I958», Clío, 38, disponible en http://clio.rediris.es [Consulta del 22 de marzo de 20I7].

22 Álvarez Osés, José Antonio et al.: La guerra que aprendieron los españoles. República y guerra civil en los textos de bachillerato (1938-1983), Madrid, Los Libros de la Catarata, 2000, pp. 167-177. 
de los que 17 contienen referencias al tema ${ }^{23}$, los autores ofrecen una interpretación descriptiva de los párrafos sobre la Guerra Civil en estos libros de texto que caracterizan genéricamente como «la versión del vencedor» ${ }^{24}$. Partiendo de la hipótesis de un modelo común de estas exposiciones, presentan un resumen de la representación habitual del inicio de la guerra, titulado «De las elecciones al alzamiento» y una reflexión sobre la denominación de la guerra, constatando una «monolítica presentación de la contienda» ${ }^{25}$. Los siguientes apartados destacan los mitos de la guerra, identificando la defensa del Alcázar de Toledo como el tema más repetido, hacen referencia a la ausencia de noticias sobre la retaguardia y la magnificación de los rebeldes militares que se pueden encontrar en los textos examinados. Un análisis de la «lexicología» de la guerra llevado a cabo por los autores llega a la conclusión de que los apelativos más frecuentes para denominar a las dos partes en conflicto fueron «rojos» $\mathrm{y}$ «fascistas». Además, los autores observan que los párrafos examinados mencionan casi exclusivamente la ayuda extranjera a la República y raras veces las ayudas recibidas por los franquistas. Resumiendo los resultados de sus investigaciones de las representaciones de la Guerra Civil en los textos de bachillerato declaran «que el tratamiento dado a la guerra civil desde 1939 a 1975 responde prácticamente a un único modelo, el primero y "tradicional", la versión oficial de los vencedores, la única autorizada, si bien sujeta a matizaciones, precisiones o recursos más o menos distanciadores ${ }^{26}$. A pesar de que el estudio mencionado usa una muestra relativamente pequeña y parcialmente diferente al material revisado para la presente investigación y la mayor extensión del periodo histórico examinado, ofrece hipótesis y resultados muy interesantes, parcialmente en concordancia con las investigaciones anteriormente resumidas, cuya coincidencia o no con las observaciones que el material coleccionado por el proyecto MANEs permite realizar tendrá que ser objeto de reflexión en los siguientes párrafos de la presente investigación.

Adicionalmente a los trabajos de investigación mencionados, se publicaron varias tesis doctorales sobre el tema de los manuales escolares franquistas. El objetivo más importante del estudio de Manuela López Marcos es «aportar algunos datos nuevos que puedan contribuir a esclarecer la naturaleza de la ideología franquista ${ }^{27}$. Según la autora, todas las ideologías políticas tienden a usar la educación como un instrumento para mantener y controlar situaciones que les favorecen, de manera que el estudio de los libros de texto promete revelar la esencia de la ideología franquista. Los libros de texto reflejan las ideologías de los grupos sociales en el poder y las diferentes formas de trasmitir sus valores a las nuevas generaciones para conservar su estatus privilegiado. Los manuales para la educación primaria son en este contexto, según el parecer de la autora, el material

23 Ibidem, p. Ioo.

24 Ibidem, p. 167.

25 Ibidem, p. I70.

26 Ibidem, pp. 225-226.

27 López Marcos, Manuela: El fenómeno ideológico del Franquismo en los manuales escolares de enseñanza primaria, Madrid, UNED, 200I, p. II. 
más importante, porque solamente una minoría social tenía acceso a la educación secundaria y superior. Uno de los resultados sorprendentes de su análisis es que «los ideólogos franquistas no hacían más que repetir hasta la exageración consignas y discursos -Dios y Patria- que ya aparecían en los textos de la monarquía Alfonsina ${ }^{28}$. Todos los elementos de la ideología franquista -nacionalismo, catolicismo, imperialismo, absolutismo, autoritarismo- se encontraron en los libros de texto de este periodo histórico, de manera que el franquismo se había limitado a recuperar los valores, las costumbres y la mentalidad del Antiguo Régimen. El análisis que la autora ofrece de la discusión sobre la idiosincrasia del franquismo llega a la conclusión de que no se trató de una ideología en un sentido estrecho, sino más bien de «una manera común de pensar de unas clases sociales históricamente dominantes, que, aunque diversas, tenían una finalidad común y a quienes los cambios políticos y sociales producidos en los últimos tiempos en España les inquietaban porque podían impedirles continuar su estatus de poder $»^{29}$. En este sentido, se podría definir el franquismo como un conjunto fundamental de creencias, cuyas prioridades esenciales fueron el nacionalismo, la unidad, la religión católica y un Gobierno fuerte y autoritario sin partidos políticos.

En el último capítulo de su estudio, López ofrece un gran número de ejemplos para apoyar su hipótesis de que la ideología nacionalcatólica del franquismo, tal y como se presentó en los libros de texto, no fue original. Un manual escolar publicado en 1924, citado por la autora, declara: «Los superiores están colocados por Dios para el bien de sus súbditos e inferiores $»^{3^{\circ}}$. En el sentido de esta argumentación, los libros de texto introducidos durante la dictadura de Franco tenían que añadir simplemente que Franco había sido elegido por Dios para restaurar la civilización cristiana. Un comentario de la autora parece interesante para la construcción del enfoque de investigación de los capítulos sobre la Guerra Civil en los libros de texto: «... el franquismo tuvo poco trabajo a la hora de actualizar los manuales escolares. Agregando simplemente unas pocas palabras, que hacían referencia a la guerra civil, los textos quedaban perfectamente encuadrados dentro del pensamiento tradicionalista del nuevo régimen, ya que la idea de fondo que se

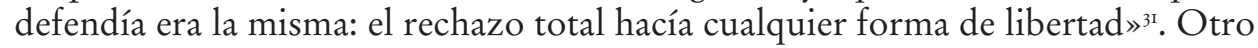
estudio defiende unas hipótesis muy similares: Raimundo Cuesta opina que «los textos escolares de la primaria en el franquismo no son más que una exageración reaccionaria y, por ello mismo, a veces cómica de la tradición anterior ${ }^{32}$. Además, esta investigación comparte también la tesis del continuismo de los textos escolares en la época franquista ${ }^{33}$, a la que nos referimos en un párrafo anterior.

Ibidem, p. I4.

29 Ibidem, p. 24.

30 Enciclopedia. Grado Preparatorio (para niñas), Madrid, Calleja, I24, p. 136, citado según LóPez Marcos, Manuela: El fenómeno ideológico del Franquismo, p. I84.

${ }^{31} \quad$ Ibidem, p. 177.

32 Cuesta Fernández, Raimundo: Sociogénesis de una disciplina escolar: la Historia, Barcelona, Pomares-Corredor, 1997, pp. 237-238.

33 Ibidem, p. 269. 
CHRISTIAN ROITH

Las hipótesis de López y Cuesta respecto a la falta de originalidad del franquismo son discutibles, pero aun, cuando se aceptan, permitirían asumir que datos importantes relacionados con la autopercepción del régimen que se distingue esencialmente de formas anteriores de gobierno en España se pueden encontrar probablemente en las representaciones de la Guerra Civil ofrecidas en los manuales de historia.

Un trabajo de investigación reciente examinó fuentes primarias muy similares, pero con un enfoque ligeramente diferente: el estudio intenta identificar los contenidos emocionales en libros de texto para la educación primaria en los primeros años de la dictadura ${ }^{34}$. El enfoque de investigación parte de la suposición de que los libros de texto sirven como herramientas para conseguir que las nuevas generaciones sientan y no solamente piensen o crean lo que se considera válido. El franquismo, dice la autora, asignó un papel extraordinario a las emociones en los manuales escolares para transmitir su ideología: los textos y las imágenes que apelan a las emociones tenían la intención de formar la estructura emocional y sentimental de la infancia. La estrategia aplicada presentó como diferentes opciones emocionales lo que en realidad no era opcional, con la esperanza de conseguir que los niños se decidieran a favor de opciones que garantizaban su seguridad y evitaban las sanciones.

La revisión de literatura sobre los manuales escolares franquistas muestra una gran variedad de enfoques científicos y resultados. A pesar del aumento considerable de la producción académica sobre el tema en las últimas dos décadas, existen todavía muchas hipótesis generales y resultados en estos estudios que necesitan ser revisados. Hasta el momento, los investigadores no examinaron las representaciones de la Guerra Civil en los libros de texto del franquismo temprano en estudios que se dedican exclusivamente a este periodo histórico, a pesar de que este enfoque promete poder ganar nuevos conocimientos sobre la construcción de la nueva identidad nacional de España por el franquismo después de la guerra. Teniendo en cuenta los estudios históricos resumidos y comentados, el análisis de este material podría contribuir al debate académico de las siguientes cuestiones, entre otras:

- ¿Son los textos sobre la Guerra Civil en los manuales escolares de historia del franquismo temprano homogéneos, tal y como algunos autores afirman, o se pueden percibir diferencias que se podrían explicar como causadas por la presencia de diferentes tendencias dentro de la ideología franquista?

- ¿Se trata de repeticiones poco originales de ideas nacionalistas antiguas o contienen nuevos elementos ideológicos?

- ¿Cómo se construye la imagen del «otro», es decir, del enemigo ideológico para construir la nueva identidad nacional franquista de España?

- ¿Qué descripción se ofrece del nuevo régimen en España, especialmente en comparación con el Gobierno anterior que se estableció democráticamente?

34 Mahamud Angulo, Kira: Adoctrinamiento emocional y socialización politica en el primer Franquismo (1939-1959) - Emociones y sentimientos en los manuales escolares de enseñanza primaria, tesis doctoral, Madrid, UNED, 2012. 
- ¿Qué perspectivas del futuro con referencia a la sociedad española ofrecen estos textos?

\section{Análisis de representaciones de la Guerra Civil española en manuales de historia del franquismo temprano}

\section{I. Metodología y datos estadísticos}

Como primer paso de la investigación se realizó una búsqueda de manuales de historia en la base de datos del proyecto MANEs que se habían publicado durante los primeros años de la dictadura de Franco. Se identificaron 36 libros con esta característica, de los que 26 contenían capítulos sobre la Guerra Civil española. Se registraron los siguientes datos: autor, título del libro de texto, lugar y año de la publicación, editorial, destinatarios y extensión del capítulo sobre la Guerra Civil. En referencia a los contenidos, se registraron los siguientes aspectos de estos textos: ¿Cómo describe el capítulo el origen de la Guerra Civil? ¿En qué términos se describe al enemigo, particularmente en contraste a la propia identidad? ¿Se mencionan acontecimientos destacados durante la guerra? ¿Cómo se describe el fin de la guerra? ¿Qué características del nuevo Gobierno nacionalista se mencionan? ¿Cómo se presentan las perspectivas del futuro para España según el texto? ¿Existen otros elementos en el texto que llaman la atención?

La identificación de los autores de 13 manuales de historia no fue posible. El resto de los libros de texto - I3- fueron redactados por autores individuales, tres de ellos por la misma persona, José Luis Asián Peña ${ }^{35}$, mientras que los demás libros tenían diferentes autores. El título más frecuente de los libros de texto es simplemente Historia de España (II veces), a veces con un apéndice $y$ de su civilización o alguna explicación adicional, como Manual de o Curso de. Algunos manuales se presentan como libros de texto combinados para geografía e historia (4 casos). La selección de libros incluye también dos obras con títulos más originales: Santa Tierra de España y Yo soy español. Ocho libros de texto se publicaron en Barcelona, también ocho en Zaragoza y seis en Madrid. Los demás lugares de publicación fueron, con un libro cada uno, Burgos, Cádiz, Gerona y Granada. La editorial con más publicaciones es la Editorial Luis Vives, también llamada Edelvives, situada en Zaragoza, con siete libros de texto. Los Hermanos Maristas fundaron esta casa en Barcelona en I889, que se trasladó al principio de la Guerra Civil a Zaragoza en la zona nacional. Otras editoriales frecuentes de manuales de historia son la Casa

35 Asián Peña empezó a trabajar como profesor de geografía e historia en el instituto Balmes de Barcelona, en 1935, manteniendo su empleo hasta su jubilación. Después del fin de la Guerra Civil, las nuevas autoridades franquistas le procesaron por haber sido masón. No obstante, recurrió su condena en 1942, de manera que nunca fue separado de su empleo. Durante la dictadura franquista se convirtió en el autor de una serie de manuales de historia oficialmente autorizados. Vid. SANCHIDrián Blanco, Carmen: «¿Qué hicieron para merecer esto? Tres profesores de bachillerato ante la depuración franquista», en Homenaje al profesor Alfonso Capitán, Murcia, Universidad de Murcia, 2005, pp. 542-544. 
Editorial Bosch en Barcelona (tres libros de texto) y Ediciones Bruño en Madrid (igualmente tres libros de texto), mientras que los demás manuales fueron publicados por editoriales diferentes. El Instituto de España, la editorial estatal que se fundó para reemplazar todas las editoriales privadas según los planes del franquismo temprano, publicó solamente dos manuales de historia, uno para el primer grado y otro para el segundo. No ha sido posible identificar la editorial de un manual.

Tres libros de texto se publicaron en 1939, entre ellos uno antes del fin de la guerra, dos en 1940, uno en 1941, dos en 1942, tres en 1944, uno en 1946, tres en 1947, cuatro en 1949, y en cada uno de los años 1952, 1953, 1954, I955, 1957, 1958 y 1962 se publicó uno de los manuales examinados. Once libros de texto definen a sus destinatarios como alumnos del "primer grado», es decir, se escribieron para niñas y niños con una edad de Io-II años, dos libros para el «segundo grado» (edad de I2-I3 años), cuatro para diferentes niveles y nueve manuales no hacen mención de los destinatarios. En algunos libros de texto sorprende la larga extensión del capítulo sobre la Guerra Civil: en siete libros se pueden encontrar más de diez páginas sobre este tema, en tres incluso más de veinte páginas. En estos últimos, el capítulo sobre la guerra ocupa frecuentemente más del ıo\% del manual completo $^{36}$. El hecho de que los autores franquistas de manuales de historia dedicaran capítulos tan largos a estos eventos muy recientes indica la gran importancia que la Guerra Civil tenía para la construcción de la nueva identidad nacionalcatólica del país que el régimen de Franco quería imponer.

A pesar de que el número de manuales de historia del franquismo temprano analizados puede parecer insignificante en comparación con el número de libros de texto generales registrados en algunas investigaciones ${ }^{37}$, los datos mencionados permiten considerarlos representativos para el periodo histórico revisado. Probablemente se publicaron todavía más libros de texto de historia en la España de Franco durante o poco después de la Guerra Civil, pero el número de libros examinados es suficiente como para permitir responder razonablemente a las cuestiones expuestas al principio de este párrafo.

\subsection{El origen de la Guerra Civil española según los manuales escolares de historia del franquismo temprano}

El relato del origen de la Guerra Civil española en los libros de texto franquistas mencionados muestra, por un lado, la repetición de varios elementos

36 Este resultado no coincide con lo constatado por Rafael VALLs, en su libro Historia y memoria escolar, op. cit., p. 40, para manuales del primer bachillerato franquista (1938-1953), donde declara que «en términos generales, la extensión dedicada tanto a la II República como a la Guerra Civil suele rondar las tres páginas, con máximos de seis páginas y mínimos de una». Esta diferencia se explica probablemente con el uso de una muestra no coincidente de manuales escolares de la época en cuestión que se deriva de intereses de conocimiento divergentes. Mientras que Valls se centra sobre todo en las interpretaciones de la Guerra Civil ofrecidas al alumnado después de 1975, este estudio enfoca en primer lugar la época del franquismo temprano.

37 Mahamud Angulo, Kira: Adoctrinamiento emocional, registra 135 libros de texto franquistas. 
básicos incluidos en todos los textos y, por otro, una amplia variedad de interpretaciones y eventos narrados que invitan a cuestionar la hipótesis de la uniformidad de este tipo de texto escolar que se defiende en algunas investigaciones. Parece que esta variedad depende fuertemente de la extensión del capítulo sobre el tema, pero también es posible que se deba a ligeras diferencias entre las orientaciones ideológicas de sus autores. La historia estándar de los eventos que llevaron al estallido de la Guerra Civil, presente en todos los manuales de historia, argumenta aproximadamente como sigue: la Constitución republicana se mostró incapaz de respetar los derechos más sagrados de la religión y de la familia y persiguió a la Iglesia y la propiedad privada. Se cometieron muchos crímenes durante la República, particularmente el incendio de iglesias y el asesinato de muchos patriotas decentes. El acontecimiento que se menciona con más frecuencia en este contexto es el asesinato del político monárquico y conservador José Calvo Sotelo por una unidad de la policía urbana llamada Guardia de Asalto y varios activistas socialistas el I3 de julio de $1933^{3^{8}}$. Todos los autores de los manuales de historia describen este incidente como la gota que colmó el vaso.

No obstante, el contexto en el cual se puede encontrar esta línea de argumentación varía según la extensión del capítulo, el año de la publicación y, muy probablemente, según la orientación ideológica del autor dentro del conjunto franquista. Los manuales de historia del franquismo temprano, es decir, aquellos publicados en 1939 y a principios de los años I940, usan un vocabulario más agresivo y excesivo que libros de texto más tardíos, cuando se refieren a los eventos mencionados. Los textos hablan, por ejemplo, no solamente del asesinato de José Calvo Sotelo, sino del «vil asesinato»; no se trata simplemente del «alzamiento» del ejército, sino del «glorioso Alzamiento Nacional» en letras mayúsculas. Los libros de texto más tempranos igualmente tienden a identificar la «invasión extranjera marxista y bolchevique» de España como uno de los orígenes de la evolución posterior ${ }^{39}$. Teniendo en cuenta esta tendencia, es decir, cierta exageración lingüística a la hora de describir la vileza del enemigo y las excelentes características del propio partido, sorprende la presencia de comentarios en un libro de texto temprano que revela hasta cierto punto la intención de llegar a comprender la motivación del enemigo. Este manual de historia de 1939 habla en su capítulo sobre la Guerra Civil de trabajadores decepcionados que fueron responsables de la revolución obrera en Asturias en 1934. "Esa gran decadencia del sentido religioso»,

${ }_{38}$ Calvo Sotelo fue probablemente la víctima de un acto de venganza después del asesinato de dos oficiales socialistas de la Guardia de Asalto. El capitán de la Guardia de Asalto Carlos Faraudo y de Micheo, militante socialista desde 193I, había sido asesinado por falangistas el 9 de mayo de 1936. Poco tiempo después, el teniente y militante socialista José del Castillo Sáenz de Tejada sufrió el mismo destino; los autores del crimen fueron pistoleros derechistas, aunque diferentes estudios no se ponen de acuerdo sobre si los asesinos fueron falangistas o carlistas. Además, Calvo Sotelo había pronunciado unos discursos extremadamente agresivos contra el Gobierno izquierdista en los debates parlamentarios. Vid. Thomas, Hugh: The Spanish Civil War, London, Penguin Books, 2003, pp. 196-198, y Preston, Paul: Franco "Caudillo de España», Barcelona, Mondadori, 1998, p. I76.

39 Montilla y Benítez, Rafael: Nociones de Geografía e Historia de España, Granada, Imprenta Editorial Urania, 1939, p. I80. 
CHRISTIAN ROITH

explica el autor, «y de la espiritualidad, favorecía a los propagandistas revolucionarios en sus intentos de hacer germinar el odio en las clases obreras y aun en la media, tomando apoyo en los egoísmos e injusticias de las clases altas, de los favorecidos por la fortuna» ${ }^{40}$. El texto citado fue el único en todos los libros de texto analizados que se refería críticamente al papel de las clases sociales altas en el estallido de la Guerra Civil. En este caso se puede llegar a suponer, sin conocer más detalles sobre la biografía del autor, que esta frase refleja en mayor grado la interpretación falangista de los eventos que la opinión de los fundamentalistas católicos. No obstante, ningún otro manual de historia franquista reproduce esta interpretación de los acontecimientos.

El paso del tiempo igualmente parece haber influido en el carácter de los capítulos de la Guerra Civil en los manuales escolares franquistas. Los capítulos en libros publicados a partir de los años 1950 tienden a ser más cortos que los textos en manuales anteriores y el vocabulario pierde una parte de la agresividad de los años inmediatamente posteriores a la guerra. Un libro de texto de la época posterior se refiere simplemente al Gobierno republicano que aumentó su extremismo sectario a partir de 1945 (un error tipográfico, C. R.) y la situación caótica de la nación que motivó el Alzamiento Nacional ${ }^{4}$. Un manual de historia publicado en 1953 admite que los españoles recibieron la proclamación de la $2{ }^{a}$ República con esperanza, antes de que la quema de iglesias, la política antimilitarista y anticlerical de Azaña, así como los atracos, las huelgas y el asesinato de Calvo Sotelo mostraran su carácter verdadero, siendo el último acontecimiento la causa que motivó el alzamiento del movimiento nacional ${ }^{42}$. El cronológicamente último libro de texto que se analizó para el presente estudio ofrece una narración poco inspirada de los eventos que llevaron al estallido de la Guerra Civili3. Todos los elementos de la historia estándar anteriormente mencionados aparecen en el capítulo correspondiente, pero el lector no puede evitar la impresión de que el único motivo para incluir este texto en el libro es la intención de la autora de obtener la necesaria autorización por parte del censor para publicar y vender el libro escolar y no tanto su verdadera convicción referente a la superioridad moral del franquismo.

\subsection{La identificación del enemigo y del partido propio}

En ninguno de los manuales de historia del franquismo temprano se puede encontrar un adjetivo que sirva para denominar a los seguidores del general

\footnotetext{
40 Pellegero Soteras, Cristóbal: Nociones de Geografía General e Historia de España, Zaragoza, Heraldo de Aragón, 1939, p. II7.

${ }_{41}$ Bosch Cusí, Juan: Historia de España, Gerona, Dalmau Carles, Pla. Editores, 1952.

42 Santamaría Abández, Álvaro: Historia Moderna y Contemporánea, Madrid, Textos Prensa Española, 1953, pp. 204-205.

43 Comas de Montáñez, María: Historia de España y de su civilización, Barcelona, Ediciones Socrátes, I962, p. I6I.
} 
Franco ${ }^{44}$. Los sujetos que actúan en los textos son muchas veces el mismo Franco o uno de sus oficiales. Se menciona el «Glorioso Movimiento Nacional» o el «Alzamiento», al igual que «La Falange», pero los textos no ofrecen una denominación común del partido propio. Por esta razón y coincidiendo con un trabajo de investigación mencionado anteriormente ${ }^{45}$, se puede suponer que los manuales de historia reflejan la construcción de la propia identidad por parte del franquismo mediante la presentación de sus seguidores como aquellos que eran diferentes del enemigo. Los autores de los libros de texto franquistas se abstuvieron de la introducción de una denominación positiva que identificase a su propio partido, siguiendo la costumbre lingüística oficial que atacó ferozmente al enemigo ideológico, unificando el partido propio mediante la implicación de «nosotros somos aquellos que se enfrentan a los malos». Un trabajo de investigación sobre el papel de la enseñanza de la historia en la formación de la identidad nacional española de I875-1975 que se fundamenta en una amplia selección de documentos y que tiene el mérito de destacar la importancia de las enciclopedias en el adoctrinamiento del alumnado de primaria durante la época franquista llega a una conclusión muy parecida: «De hecho, la propia esencia del nacionalcatolicismo franquista era negativa, su verdadero propósito no era inspirar una nueva España, sino legitimar la antigua» ${ }^{46}$.

Un análisis más detenido de los adjetivos y las denominaciones utilizados para identificar al enemigo encuentra algunas variaciones entre los diferentes textos, pero una relación entre estas diferencias y factores como la orientación ideológica diferente de los autores o periodos temporales diferentes no parece existir. Un libro de texto incluso prescinde de la introducción de una denominación específica del enemigo ${ }^{47}$, mientras que otros manuales usan entre uno y cuatro diferentes adjetivos o sustantivos, cuando se refieren al partido opuesto. La denominación más frecuente es simplemente «los rojos», que se encuentra en prácticamente todos los textos, a veces junto a variaciones más o menos creativas. En libros de texto tempranos se pueden encontrar descripciones como «partidos subversivos, bandidos, asesinos y comunistas rusos», así como denominaciones como la «Masonería Internacional» o la «Internacional Comunista», acompañadas ocasionalmente por identificaciones menos agresivas como el «gobierno republicano y comunista» o simplemente los «extremistas». Otras variaciones son el «Frente Popular», la «Anti-España» o simplemente lo «malo», y, en un caso, las «Brigadas Internacionales». De vez en cuando hay referencias al «Marxismo» y los «Marxistas», pero estos términos se usan con menos frecuencia que las otras denominaciones.

44 Esta observación no coincide con los resultados de la investigación de Álvarez Osés, José Antonio et al.: La guerra que aprendieron los españoles, op. cit., p. 175, que habla del frecuente uso del término «fascistas» en los manuales de historia para denominar a los seguidores de Franco.

45 Campos Pérez, Lara: Representando al enemigo, 2008.

46 Boyd, Carolyn P.: Historia Patria. Política, historia e identidad nacional en España: 1875-1975, Barcelona, Pomares-Corredor, 2000, p. 222.

47 Bosch Cusí, Juan: Historia de España, Gerona, Dalmau Carles, Pla. Editores, I952. 
REPRESENTACIONES DE LA GUERRA CIVIL ESPAÑOLA EN MANUALES DE HISTORIA

DEL FRANQUISMO TEMPRANO

CHRISTIAN ROITH

\subsection{El transcurso de la guerra}

Las descripciones del transcurso de la guerra varían considerablemente entre los diferentes libros de texto. Los manuales con capítulos largos sobre la Guerra Civil, es decir, aquellos con diez páginas o más sobre el tema, tienden a ofrecer relatos detallados de las campañas militares desde la perspectiva de los militares nacionalistas rebeldes. Uno de estos libros estructura el capítulo correspondiente con subtítulos como «Primer Año del glorioso Alzamiento Nacional», «Segundo Año Triunfal» y «Tercer Año Triunfal (Año de la Victoria)» ${ }^{4}$. No obstante, incluso los textos en estos largos capítulos no mencionan, al igual que los demás libros de texto, un elemento esencial del conflicto: la intervención de las tropas de la Alemania nazi y la Italia fascista, en particular de su aviación, la Legión Cóndor y la Aviazione Legionaria. Solamente se pueden encontrar unas referencias poco significativas a la contribución militar extranjera a la Guerra Civil ${ }^{49}$ y el conflicto se representa en todos los manuales consultados como un asunto puramente español, en el que los españoles buenos defienden la civilización cristiana y occidental contra la amenaza de la barbarie comunista.

\subsection{Eventos destacados de la guerra}

A pesar de que muchos manuales de historia franquistas no mencionan eventos destacados en la guerra (I2 de 26), la mayoría ofrece relatos densos y metafóricos que representan el carácter de las partes en guerra. En el único libro de texto publicado antes del fin de la guerra, la ejecución del líder de la Falange, José Antonio, aparece como uno de los eventos más destacados ${ }^{50}$, mientras que el incidente más frecuentemente mencionado en los demás manuales es el llamado «heroísmo durante la defensa del Alcázar de Toledo» rrar como sigue:

Entretanto, el Alcázar de Toledo resiste valerosamente. «Si usted no se rinde, fusilaré a su hijo Luis.» Esta conversación, que por teléfono mantiene el comandante enemigo y el defensor del Alcázar, Moscardó, se interrumpe para que hablen padre e hijo. «-Hola papá! - ¿Qué pasa? - Nada: me fusilarán si tú no te rindes. - ¿Y tú, qué piensas? - ¿Que no debes rendirte, papá! -Lo esperaba de ti. Encomiéndate

${ }^{8}$ Vid. Pellegero Soteras, Cristóbal: Nociones de Geografía General e Historia de España, Zaragoza, Heraldo de Aragón, I939.

49 «Entre tanto, la guerra española había ido apasionando cada día más en Europa y las dos ideologías predominantes en el continente prestaban su ayuda a los contendientes». Asıá́n PeÑa, José Luis: Nociones de Historia - Edades Moderna y Contemporánea, Barcelona, Casa Editorial Bosch, 1955, p. 347 .

so Anónimo: Manual de Historia de España, Primer Grado, Madrid, Instituto de España, I939, p. 75 .

${ }_{51}$ Álvarez Osés, José Antonio et al.: La guerra que aprendieron los españoles, op. cit., p. 172, ofrece esta misma observación. 
a Dios a da un fuerte ¡Viva España! y un fuerte ¡Viva Cristo Rey! y vete tranquilo a la muerte. Tu padre no se rinde. - Un beso, papá. - Adiós, hijo mío: un beso muy fuerte» ${ }^{52}$.

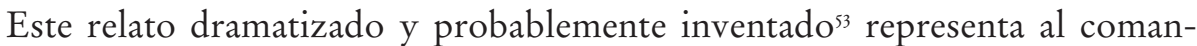
dante republicano como un asesino despiadado que no respeta las reglas fundamentales del derecho de guerra, mientras que el general nacionalista al mando del Alcázar y su hijo aparecen como nobles defensores de la familia y la religión. De esta manera, el evento simboliza el choque entre los españoles buenos y los enemigos extranjeros que invadieron el país, lo que hizo el estallido de la Guerra Civil inevitable. La intención de esta parte del libro de texto no es tanto la transmisión de conocimientos teóricos sobre el transcurso de la guerra, sino la manipulación de los sentimientos de los estudiantes para conseguir que se identifiquen plenamente con el régimen de Franco, sintiendo odio contra los enemigos.

\subsection{El fin de la guerra y las perspectivas futuras para España}

Con la excepción del manual de historia publicado antes del fin de la Guerra Civil que menciona que «la guerra sigue triunfal y España renace a una nueva vida de gloria y poderío» ${ }^{54}$, la mayoría de los libros de texto citan la breve declaración de Franco, quien manifestó lacónicamente que «la guerra ha terminado» el I de abril de i939. Un libro de texto de los primeros años de la dictadura añade la información que el Papa, «haciendo suya la victoria, nos bendice» y vaticina un futuro espléndido para Españass. A continuación, la lucha de la llamada División Azul -un cuerpo de voluntarios españoles que lucharon con las tropas de Hitler en el frente oriental contra la Unión Soviética- se presenta como el ejemplo de unos valientes españoles que siguen luchando en un país extranjero por los mismos valores que acaban de imponerse en España.

Todos los libros de historia analizados, con la excepción de solamente cuatro, ofrecen al final del capítulo sobre la Guerra Civil un resumen de sus resultados más importantes y una previsión del futuro desarrollo de España. Mientras que la descripción del fin de la guerra varía poco en los diferentes libros de texto, los aspectos destacados en los párrafos sobre el futuro del país se diferencian considerablemente. Las variaciones observadas están vinculadas con alta probabilidad a ligeras diferencias entre las orientaciones ideológicas de los autores de los libros

52 Muntada Bach, José: Santa Tierra de España, Barcelona, Imprenta-Editorial Altés, 1942, pp. 314-315. La cita trascribe el texto del manual con sus faltas de ortografía («papá» con acento, por ejemplo).

33 Vid. Bullón de Mendoza Gómez de Valugera, Alfonso y Togores Sánchez, Luis Eugenio: El Alcázar de Toledo: final de una polémica, Madrid, Actas, 1997.

54 Anónimo: Manual de Historia de España, Primer Grado, Madrid, Instituto de España, I939, p. 76.

"Muntada Bach, José: Santa Tierra de España, Barcelona, Imprenta-Editorial Altés, 1942, p. 330 . 
de texto, por una parte, y, por otra, reflejan la evolución política del régimen en los primeros años después del fin de la guerra. Los libros de texto más tempranos, es decir, aquellos publicados hasta aproximadamente 1942, tienden a destacar la recuperación de los valores tradicionales, como, por ejemplo, el patriotismo, la moralidad y la religión, como el resultado más importante de la victoria de Franco. La mayoría de estos textos contiene adulaciones al dictador Franco y declaraciones en el sentido de que España había recuperado su lugar bien merecido entre las naciones, es decir, arriba y cerca de $\operatorname{Dios}^{56}$.

Otras conclusiones originales se pueden encontrar en el manual de historia de Pellegero anteriormente mencionado ${ }^{57}$. Antes de presentar a los miembros del nuevo Gobierno como personalidades destacadas, el autor intenta documentar la superioridad de los intelectuales tradicionalistas sobre sus oponentes, respondiendo de esta manera al argumento conocido, pero no mencionado, de que la mayoría de los intelectuales en el mundo apoyaron la República. Desgraciadamente, su intencionada mención de nombres supuestamente conocidos no apoya el argumento presentado, ya que ninguno de los intelectuales tradicionalistas que aparecen en este párrafo tuvieron una importancia destacada y duradera en la vida cultural de España, quizás con la excepción de Menéndez Pelayo, quien murió en ı9ı2, y José María Pemán, un longevo autor y político católico fundamentalista.

Los manuales de historia de años posteriores siguen refiriéndose a la recuperación de la fe religiosa como uno de los resultados importantes de la guerra, pero cambian de enfoque y empiezan a presentar la política social de Franco como una de las consecuencias más importantes de la victoria nacionalista. Un libro de texto publicado en 1947 menciona en primer lugar la reconstrucción nacional organizada por el Servicio de Regiones Devastadas como uno de los logros del nuevo régimen, y destaca a continuación el establecimiento del Consejo de Investigaciones Científicas y la introducción de los llamados sindicatos verticales. Esta última organización unió la patronal y los trabajadores, después de prohibir los sindicatos que existieron anteriormente, como, por ejemplo, la CNT anarquista y la UGT socialista. El último párrafo menciona una serie de nuevas instituciones públicas establecidas con la intención de solucionar la cuestión social, declarando que «... el nuevo Estado ha sabido resolver la situación de las clases más modestas, apartándolas así de las ideologías extremistas que tantos males causaron a España en los años anteriores a $1936 »^{58}$. Otro libro de texto, publicado solamente dos años más tarde, subraya igualmente la mejora de la situación de los trabajadores y los pobres como un logro del nuevo régimen, definiendo España como un Reino Católico y Social, gobernado por Franco,

\footnotetext{
56 Pemán, José María: La Historia de España contada con sencillez, Cádiz-Madrid, Escelicer, 1944, p. 222.

57 Pellegero Soteras, Cristóbal: Nociones de Geografía General e Historia de España, Zaragoza, Heraldo de Aragón, 1939, pp. 134-135.

58 Sobrequés Vidal: Santiago, Hispania - Curso de Ampliación, Barcelona, Ediciones Teide, 1947, p. 206.
} 
antes de que un rey o regente le siga ${ }^{59}$. Ediciones posteriores de este manual mantienen la misma argumentación. Algunos de los libros de texto de estos años acompañan la descripción del progreso de España en los primeros años bajo el nuevo régimen con el comentario de que esperan que España pueda recuperar el poder y la grandeza que su imperio poseyó en el pasado, si sigue en el camino mostrado por Franco.

Desde hace aproximadamente dos décadas, la historiografía española investiga más intensamente la dictadura de Franco. Los historiadores de la educación estudiaron diferentes temas, como, por ejemplo, la autorrepresentación del régimen dictatorial en libros de texto. Estas investigaciones se fundamentaron en la hipótesis de que la ideología de los grupos sociales en el poder, así como su concepto de la transmisión de sus valores a las nuevas generaciones, se reflejan en los manuales escolares. Una revisión de estudios españoles de libros de texto franquistas identificó diversas hipótesis generales, como las siguientes:

- La argumentación en manuales de historia franquistas no cambió de 1939 a I970.

- Los libros de texto construyeron la nueva identidad nacional española en el sentido del régimen dictatorial como opuesta al «otro», es decir, al enemigo ideológico.

- La ideología nacionalcatólica del franquismo, tal y como se presenta en los libros de texto, no fue original y simplemente repitió los argumentos de periodos históricos anteriores.

- Los textos y las imágenes en los libros de texto franquistas intentaron manipular la estructura emocional y sentimental de los niños.

El análisis de representaciones de la Guerra Civil en 26 manuales de historia pertenecientes al proyecto MANES en Madrid aprovechó estas hipótesis para la construcción de diversas preguntas de investigación. La larga extensión de un gran número de capítulos sobre este tema en los libros de texto sugiere que el tema de la Guerra Civil era de especial importancia para la construcción de la nueva identidad nacionalcatólica intencionada por el régimen dictatorial.

El examen de los textos mencionados no ha encontrado resultados que invaliden las hipótesis anteriores, pero se sugiere matizarlas como sigue: cuando presentan las razones por el estallido de la Guerra Civil, narrando su transcurso e informando sobre su fin, todos los manuales de historia reproducen los mismos o, al menos, muy similares elementos de una narración que se podría denominar la historia estándar. No obstante, un examen más detenido de los textos revela algunas variaciones que se deben probablemente a diferencias en las orientaciones ideológicas de sus autores y el paso del tiempo. Los textos más tempranos usaron un vocabulario más agresivo, es decir, términos como fascismo, totalitarismo, raza, sangre, imperio, etc., aparecieron con más probabilidad, mientras que otros conceptos como catolicismo, el movimiento, el reino y la subsidiariedad

59 Anónimo: Geografía e Historia, Zaragoza, Editorial Luis Vives, 1949. 
CHRISTIAN ROITH

llegaron a ser más importantes en libros de texto de años posteriores. El autor de un libro de texto temprano incluso declaró que las clases privilegiadas habían sido también responsables del conflicto, reproduciendo de esta manera una tesis falangista.

El análisis del vocabulario utilizado para denominar al enemigo político e ideológico no pudo identificar diferencias relacionadas con los factores anteriormente mencionados. Los textos en los manuales no usan adjetivos para identificar al partido propio, pero construyen la nueva identidad nacional indirectamente, invitando a los alumnos a considerarse buenos españoles que son diferentes del enemigo maligno. Persiguiendo este fin, los textos y las imágenes de los manuales no fueron diseñados en primer lugar para transmitir contenidos cognitivos al alumnado, sino con el objetivo de la manipulación emocional. Esta intención queda especialmente evidente en las narraciones de eventos destacados en la Guerra Civil, donde habitualmente se enfrentan luchadores nobles y valientes por la buena causa al enemigo malvado. Mientras que los relatos del transcurso de la guerra no muestran diferencias significativas entre los libros de texto, se pueden constatar variaciones considerables en aquellos párrafos que tratan el tema de los resultados de la guerra y de la futura perspectiva para España. Los libros de texto de los primeros años de la dictadura tienden a destacar la recuperación de los valores tradicionales, como el patriotismo, la moralidad y la religión, mientras que los manuales de los años posteriores mencionan la política social de Franco y la mejora de la situación de las clases bajas y de los pobres como el resultado más importante de la victoria de las fuerzas nacionales. En estos textos se pueden observar diferencias que se deben probablemente a orientaciones ideológicas diferentes de los autores y el paso del tiempo.

El argumento que los manuales de historia franquistas no son originales y repiten ideas tradicionales procedentes de épocas anteriores parece convincente a la luz de los ejemplos presentados por el estudio correspondiente ${ }^{60}$. Esta hipótesis es correcta en lo referente a las representaciones de la historia general de España en los manuales de historia franquistas, pero necesita ser modificada en lo que se refiere a los capítulos sobre la Guerra Civil. Elementos estructurales de la narración de este evento, como el motivo del conflicto ideológico entre las fuerzas del bien que no se denominan exactamente y los «rojos»; la mención de la nueva fuerza política de la Falange que intentó reestructurar la sociedad española y que declaró que las clases sociales privilegiadas fueron igualmente responsables de los conflictos sociales, y, finalmente, la idea de la necesidad de someterse al Caudillo, legitimado por la providencia divina, aunque no por su pertenencia a una dinastía real, no se pudieron encontrar en manuales de historia anteriores, de manera que se pueden considerar nuevas y originales contribuciones a los libros de texto de historia publicados y usados durante la época de Franco.

Las representaciones unilaterales y adulteradas de la Guerra Civil en los manuales de historia del franquismo temprano fueron una herramienta en las manos

6o López Marcos, Manuela: El fenómeno ideológico del Franquismo en los manuales escolares de enseñanza primaria, Madrid, UNED, 200I, p. 177. 
del régimen franquista que sirvió para transmitir su ideología -no exactamente definida, como hay que admitir-al alumnado, contribuyendo de esta manera al mantenimiento de su poder durante casi cuatro décadas. Las autodescripciones del régimen en los textos analizados revelan una ideología nacionalcatólica extremadamente autoritaria que se acercó ocasionalmente a conceptos totalitarios. Las diferencias de opinión internas debido a diversas tendencias que competían en el conjunto del franquismo, así como diferentes puntos de vista en lo referente a la evaluación de diversos aspectos de la política del régimen que se reprodujeron ocasionalmente en los manuales de historia, no llegaron nunca a ser lo suficientemente importantes como para poner en peligro la imagen de unidad del régimen dictatorial ${ }^{61}$.

${ }_{61}$ Quiero expresar mi profunda gratitud a Gabriela Ossenbach Sauter, catedrática de Historia de la educación y directora del Departamento de Educación de la UNED, presidenta de la Sociedad Española de Historia de la Educación y directora del proyecto MANEs, no solamente por haberme concedido acceso a los impresionantes fondos del proyecto, sino también por la ayuda prestada a la hora de localizar los manuales escolares de historia franquistas analizados en el presente estudio. 